\title{
Ectopic Allergic Contact Dermatitis- An Uncontemplated Entity to Epoxy Resins
}

\author{
Chowdhry S, Soni P, D'souza P* and Kaur I \\ Department of Dermatology, ESI PGIMSR \& Model Hospital, India
}

*Corresponding author: Paschal D’souza. MBBS, MD, Dermatology Professor, ESI PGIMSR \& Model Hospital, New Delhi, 110015, India, Tel: 9868215047; Email: paschaldsouza@yahoo.com

\section{Case Report \\ Volume 4 Issue 3}

Received Date: August 05, 2019

Published Date: August 23, 2019

DOI: $10.23880 /$ cdoaj- 16000186

\section{Abstract}

Epoxy resins are frequently used in electrical insulation, paints, inks \& PVC products. DGEBA resin (diglycidyl ether of bisphenol A) is one most important allergen in epoxy resin and is known to cause allergic and airborne contact dermatitis. A professional worker whose work pertained to installation of new electrical meters presented with eczematous dermatitis over neck and forearm. Patch test showed positive reaction to epoxy resins. Allergic Contact Dermatitis (ACD) to epoxy resins is usually directly related to the occupation of the individual in most cases. Dissemination of relevant information about potential sensitization to materials containing epoxy resins and pre exposure screening patch tests of workers in occupations where exposure to epoxy resins is anticipation of potential contact dermatitis is highly recommended.

Keywords: Ectopic contact dermatitis; Epoxy resins

\section{Introduction}

Contact dermatitis is the most common type of occupational dermatoses [1]. Allergic contact dermatitis (ACD) to epoxy resin is found to be the second most common allergen in a study on occupational dermatoses, being positive in $5.94 \%$ of all ACD cases amongst workers [2] but presence of dermatitis at a distant site (Ectopic contact dermatitis) is quite an uncommon feature reported till date. Epoxy resins are widely used in paints, adhesives \& insulation of electrical cables. Skin contact with such resins is known to cause Irritant, Allergic, Air borne Contact dermatitis etc. Here we are presenting a case of Ectopic allergic contact dermatitis to the insulation material covering the electrical cables which are known to have significant component of epoxy resins in them.

\section{Case Synopsis}

A 40 year old male presented to the dermatology outpatient department with ill defined, erythematous, mildly exudative \& scaly plaques over both sides of the neck and over left cubital fossa. Also there was periorbital erythema, xerosis and mild scaling on these affected sites (Figure 1). His fingers were uninvolved and spared although there was evidence of mild xerosis. All these skin lesions were persisted since past one year with exacerbations in hot and humid weather. The patient is presently employed as a worker in the electricity department wherein his job pertains to fixing of electric cables in the newly installed electric meters in premises after removing the insulation covering of these electric wires. He gives history of using rubber gloves at his work. 
A clinical differential diagnosis of airborne contact dermatitis and ectopic allergic contact dermatitis were considered and skin biopsy from the lesion was sent for histopathology which revealed hyperkeratosis, mild acanthosis, spongiosis with perivascular infiltrate and eosinophils (Figure 2). The patient was subjected to patch testing with Indian standard series (Table 1) obtained from Systopic Pharmaceuticals (P) Ltd, New Delhi. The standard patch testing technique using aluminum Finn chambers was undertaken and the results of the same were interpreted as recommended by ICDRG. Patch test reading after 72 hours showed erythema and mild induration with epoxy resins (grade 1 reaction) (Figure 3 ). It was found that his absolute eosinophil count and serum IGE were slightly increased whereas other routine biochemical investigations were within normal limits.

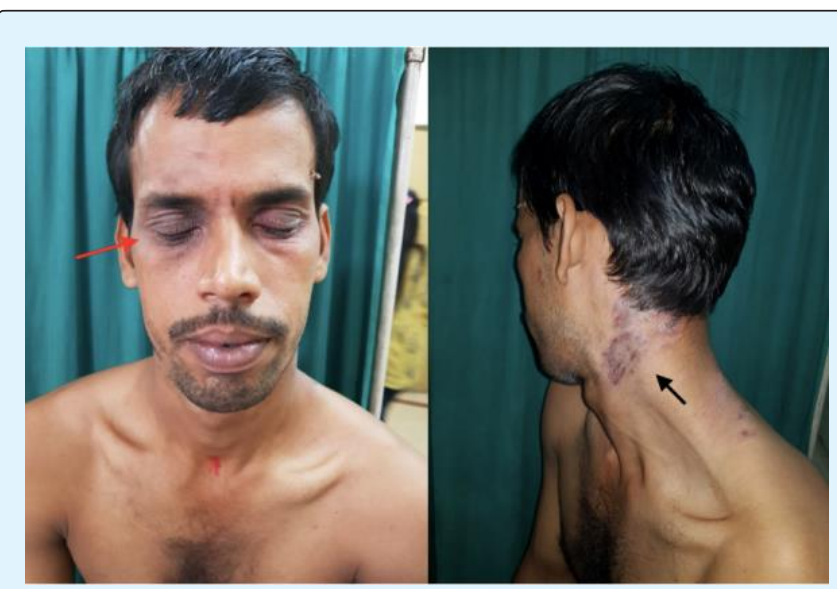

Figure 1:1a-(Red arrow): Scaling and erythema around eyes. 1b- (Black arrow) eczematous plaques on neck.

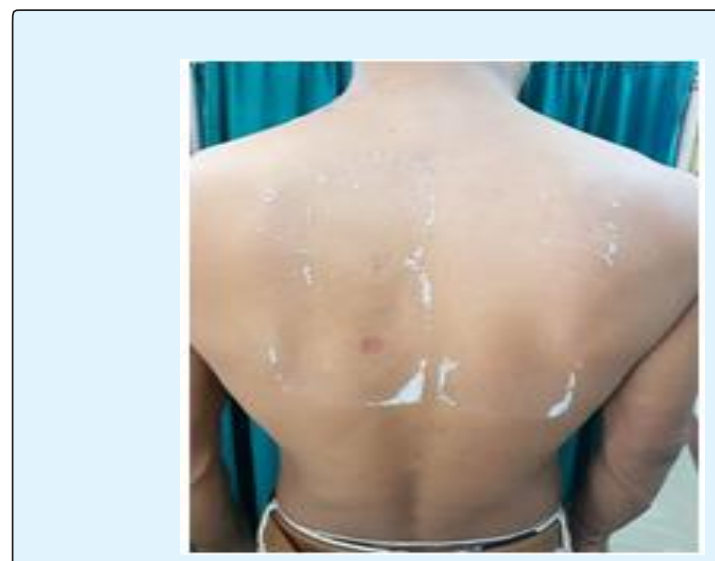

Figure 2: 1+ reaction (positive patch test) with epoxy resins.

D'souza P, et al. Ectopic Allergic Contact Dermatitis- An Uncontemplated Entity to Epoxy Resins. Clin Dermatol J 2019, 4(3): 000186.

\begin{tabular}{|c|c|}
\hline 1 & Vaseline \\
\hline 2 & Wool Alcohol(Lanolin) \\
\hline 3 & Peru balsam \\
\hline 4 & Formaldehyde \\
\hline 5 & Mercaptpbenzpthiazole \\
\hline 6 & Potassium dichromate \\
\hline 7 & Nickel sulphate \\
\hline 8 & Cobalt sulphate \\
\hline 9 & Colophony \\
\hline 10 & Epoxy Resins \\
\hline 11 & Parabens Mix \\
\hline 12 & Para-phenylinediamine \\
\hline 13 & Parthenium \\
\hline 14 & Neomycin Sulphate \\
\hline 15 & Benzocaine \\
\hline 16 & Chorocresol \\
\hline 17 & Fragrance Mix \\
\hline 18 & Thiuram Mix \\
\hline 19 & Nitrofuro Zon \\
\hline 20 & Black rubber mix \\
\hline
\end{tabular}

Table 1: List of Antigens: Indian Standard Battery.

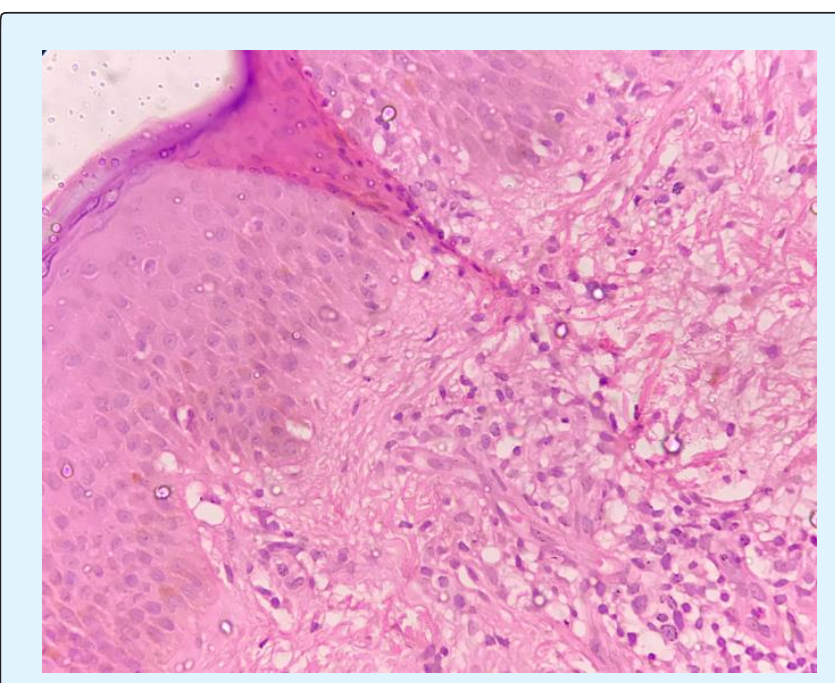

Figure 3: H \& E (40x) stain showing spongiosis with mild lymphocytic and eosinophilic infiltrate.

In view of unaffected fingers and evidence of dermatitis at distant sites like neck and cubital fossa a final diagnosis of ectopic allergic contact dermatitis due to epoxy resins was made and airborne contact dermatitis (ABCD) was ruled out on the basis of history, clinical examination, biochemical tests and absence of positive patch test for common airborne allergens such as parthenium, potassium dichromate and aerosols of 
microscopic volatile substances having potential to cause / precipitate ABCD. Patient was treated with oral steroids in tapering doses, oral antihistaminics, topical steroids and emollients. He was advised to use vinyl gloves instead of conventional rubber gloves while working and handling the insulated cable wires as the former is impermeable to epoxy resins.

\section{Discussion}

Skin sensitization due to epoxy resin has been reported since the late 1950s [3] Epoxy resins are organic chemicals that contain more than one epoxy group. 75\% of the epoxy resins currently used worldwide are derived from diglycidyl ether of bisphenol A (DGEBA; CAS no. 1675-54-3) [4]. DGEBA resin (DGEBA-R) is also the most important sensitizer in epoxy systems but contact allergies to other epoxy resins, hardeners and modifiers such as reactive diluents, also occur. Epoxy resins have a wide spectrum of useful properties and enjoy extensive usage in electrical wirings owing to its low shrinkage, good adhesion to many metals and resistance to moisture, thermal \& mechanical shock. They are widely used in adhesives, high performance coatings, paints, inks, PVC products, etc. [5]. In one of the largest series reported,

$29 \%$ of contact dermatitis cases were due to epoxy resin compounds used in electrical insulations [6]. In a Spanish study of 449 construction workers with suspected occupational contact dermatitis, $7.5 \%$ were allergic to epoxy resi [7]. In this case mainly three differential diagnosis were kept in mind, mainly, airborne contact dermatitis (ABCD), auto-eczematisation (AE) and ectopic allergic contact dermatitis (EACD). On the basis of negative patch test to other common airborne allergens such as parthenium etc. and presence of eczematous changes localized to only one side of the neck which was alleged site of contact, along with uninvolved common sites (axilla, $\mathrm{V}$ of the chest ),ruled out the possibility of ABCD. Similarly absence of eczematous lesions over the primary site eliminated the probability of autoeczematization. The clinical picture and relevant investigations support the diagnosis of EACD. Ectopic contact dermatitis is a condition when allergens may indeed be transferred from one site to the other potentially susceptible site on the body usually by contact with hands. In these cases the patients present with signs and symptoms of dermatitis at distant sites, with or without associated periorbital edema [8].

The present case is of a worker employed in the electrical department whose main work was to fix new electric meters and in doing so electric wires were de roofed and uninsulated at their terminal ends by scraping the external covering using a hand-held indigenous knife. The denuded tipped electric cables were inserted and joined in the newly installed electric meter unit. Epoxy resin is a known constituent of such insulation coatings of electrical wires which are manufactured in such a manner so as to enhance performance of these conduits. The humid climate of the patient's present place of working in a country with tropical climatic conditions and the history of profuse sweating while at work, often resulted in itching of his neck and face. In an attempt to wipe off the sweat and scratch the local area the patient frequently touched his other body parts such as both sides of neck, left cubital fossa (being a right handed person) resulting in manifestation of features dermatitis in those parts. This led to the appearance of allergic contact dermatitis at body sites distant from the primary contact area (Ectopic ACD). The hands despite being the primary site of contact to the alleged allergen were uninvolved probably due to the use of rubber gloves, albeit they too are not wholly impervious.

It is well known that heavy-duty vinyl gloves or gloves made with multilayered folio-type material give reasonable protection to workers handling such kind of material having his concentration of epoxy resins Silicone-based barrier creams may be of some additional benefit although only few studies have been conducted in this regard. Regular cleaning and maintenance of epoxyresin-contaminated equipment and workplaces at periodic intervals is essential [9]. It is also mandatory to educate and inform the worker to avoid both direct and indirect contact of these potentially harmful resins to other unprotected skin sites. It is further suggested that the manufacturer of these materials should provide relevant information about sensitization potential of these materials and pre exposure screening by patch tests of workers in this occupation should be performed so as to decrease the incidence of occupational dermatoses.

Integration of case reports is necessary to visualize the atypical presentation of allergic contact dermatitis where only ectopic sites are involved and primary exposed area is spared. The present case is cited not only to enlighten the clinician to aptly differentiate between the three similar clinical entities of ABCD, AE, EACD but also to elucidate the importance of proper history taking and examination particularly those pertaining to occupational dermatoses. The possibility of potential risk necessitates prior communication to prevent occupational allergic dermatitis in such cases so as to avoid undesirable loss of 


\section{Clinical Dermatology Open Access Journal}

man-hours, unwanted financial implications and unnecessary litigation.

\section{References}

1. Bhatia R, Sharma VK (2017) Occupational dermatoses: An Asian perspective. Indian J Dermatol Venereol Leprol 83(5): 525-535.

2. Uter W, Ruhl R, Pfahlberg A, Geier J, Schnuch A, et al. (2004) Contact allergy in construction workers: Results of a multifactorial analysis. Ann Occup Hyg 48(1): 21-27.

3. Cronin E (1980) Contact Dermatitis. $1^{\text {st }}$ (Edn.), In: Cronin E (Eds.), Edinburgh, London and New York. Churchill Livingstone.

4. Pham H Q, Marks M J (2005) Epoxy resins. In: Ullmann's Encyclopedia of Industrial Chemistry, $7^{\text {th }}$ (Edn.), John Wiley \& Sons pp: 156-156.

5. Jensen CD, Andersen KE (2003) Two cases of occupational allergic contact dermatitis from a cycloaliphatic epoxy resin in a neat oil: Case Report. Environ Health 2: 3.

6. Jolanki R (1991) Occupational skin diseases from epoxy compounds. Epoxy resin compounds, epoxy acrylates and 2,3-epoxypropyltrimethyl ammonium chloride. Acta Derm Venereol Suppl Stockh 159: 1-80.

7. Conde-Salazar L, Guimaraens D, Villegas C, Romero A, Gonzalez MA (1995) Occupational allergic contact dermatitis in construction workers. Contact Dermatitis 33(4): 226-230.

8. Tomb RR, Lepoittevin JP, Durepaire F, Grosshans E (1993) Ectopic contact dermatitis from ethyl cyanoacrylate instant adhesives. Contact Dermatitis 28(4): 206-208.

9. Rademaker M (2000) Occupational epoxy resin allergic contact dermatitis. Australas J Dermatol 41(4): 222-224. 